\title{
Characteristics and Solutions of Chinese Rural Elderly's Poverty: Meta Analyses
}

\author{
Erpeng Liu ${ }^{1,}$, Dongfang $\mathrm{Li}^{2,}$, $*$ \\ ${ }^{1}$ Center for Social Security Research, Wuhan University, Wuhan, Hubei, China \\ ${ }^{2}$ School of Public Administration, Zhongnan University of Economics and Law, Wuhan, Hubei, China \\ aemail: whubest@163.com, bemail:121399188@qq.com \\ *Corresponding author: Dongfang Li
}

Keywords: rural elderly poverty, family retirement, social security level.

\begin{abstract}
The weakening of family pension capacity and the increase of self-vulnerability make it easier for rural elderly to fall into poverty. This paper argues that due to the multidimensional nature of poverty and its cohesiveness, the definition of elderly's poverty in rural China should set standards that cover economic, health and spiritual dimensions. Objectively, the causes of the elderly's poverty in rural China mainly include the income, family pension and security system. Chinese rural elderly's poverty shows obvious regional, gender and age differences. In the process of advancing the current preferential poverty alleviation policy, improving the rural elderly's security supply level, strengthening the basic role of family pension security, improving the community old-age service system, and innovating the elderly's poverty relief method have become key measures to resolve rural poverty in rural areas.
\end{abstract}

\section{Introduction}

The elderly tends to a group with a high incidence of poverty. In the process of demographic transition, the incidence of poverty is decreasing for all, but relatively speaking, the poverty reduction of the elderly may be small or even stagnant [1]. From a global perspective, although developed countries have established a comprehensive system of the elderly's security, the problem of the elderly's poverty in developed countries is also more serious. A study of the elderly's poverty in OECD countries showed that the poverty line was defined as $50 \%$ of the median income per capita of the family, and the average incidence of old-age poverty in the OECD member countries in 2014 was 12.5\%. Among them, Australia (25.7\%) and South Korea (45.7\%) have a much higher incidence of old age poverty than other member countries [2].

China has the largest age group in the world and is one of the fastest and most severely aging countries in the world. By the end of 2017, China's elderly population over 60 years old was 241 million, accounting for $17.3 \%$ of the total population. By 2050, the size of the elderly population will exceed 400 million, and its share of the total population will exceed 30\% [3]. However, in stark contrast to the rapid development of aging, China's economic base for population aging is still relatively weak, the construction of the elderly's security system is relatively lagging, and family support for the elderly is becoming weaker. In the past 40 years of reform and opening up, the people's living standards have continued to improve. Especially after the implementation of the precise poverty alleviation policy, the incidence of population poverty has declined rapidly. According to the National Bureau of Statistics, the incidence of poverty in China has dropped from $10.2 \%$ in 2012 to $3.1 \%$ in 2017. Despite this, the incidence of poverty among the elderly is still high. Studies have shown that the incidence of poverty among the elderly in China is as high as $20 \%$, and it shows the characteristics of uneven distribution in urban and rural areas and regions [4-5].

\section{The concept and characteristics of rural elderly poverty.}

At present, the academic research on China's poverty problem is relatively lagging. The previous 
research is mainly descriptive and puts forward the poverty risk faced by Chinese elderly people [6]. Later, some scholars used the Engel coefficient method, the poverty income line method and the subjective sensory method to measure the relative poverty level of the elderly [7]. On this basis, Yang (2010) further measured the absolute poverty standards of the elderly and calculated the number of elderly poor in China [8]. In addition, some scholars have suggested that household type, demographic characteristics and cultivated land conditions are the key factors that lead to differences in poverty and affluence among households [9], and the elderly's poverty has cumulative and continuous nature, which has a great relationship with its entire life course. According to the weak/advantage accumulation model, poverty in the old age is the result of the inferior accumulation in the individual life course [10].

Numerous literature studies have shown that poverty is multi-dimensional, including economic, social, and environmental aspects. Since poverty is multidimensional, it is difficult to measure. Xie (2015) found that the minimum living security and residential pension insurance have a weak impact on urban poverty among the elderly. The minimum living security has not reduced the poverty of the rural elderly, but increased the poverty of the rural elderly, while the resident pension insurance has significantly reduced the multidimensional poverty of rural elderly [11]. Wang and Wang (2014) proposed that the poverty of the elderly should be measured in terms of economic conditions, physical health and psychological conditions, and the three dimensions of poverty, health and psychology of rural elderly should be [12]. Ma et al (2016) constructed the Multidimensional Poverty Index (MPI) for the elderly from four dimensions: health, economic security, standard of living and social participation. In application to the proportional response variable regression model and binary response model, they further analyzed the poverty-reducing factors of the multidimensional poverty in the elderly at the community level and the family level [13]. Liu and Wang (2017) decomposed old age poverty into three dimensions: economic poverty, healthy poverty and mental poverty [14].

From a single economic perspective, the living standards of rural elderly have improved considerably compared with the economic situation. However, based on the perspective of social development, the living standards of rural elderly have not been synchronized with economic development. The pluralism in the definition of poverty determines the multiple perspectives of analyzing the elderly's poverty and the multi-dimensionality of defining the elderly's poverty. As in the past, the definition of poverty in the academic circles was mainly based on economic income, and later gradually evolved into consumption expenditure, viability and fragility of livelihoods [15]. In the understanding of rural poverty, simply emphasizing the income situation of rural elderly is far from enough, which is also extremely one-sided. The elderly's poverty is a collection of multiple dangers and uncertainties. It is related to a series of weak living conditions. The definition of rural poverty must consider individual factors, family status and social security developmental orientation and so on. [16].

The factors that affect the living conditions of rural elderly are mainly dependent on their income and expenditure, health level and mental state after entering the old state. Firstly, according to Sen, there is a "kernel" of absolute poverty in the concept of poverty, that is, whatever the relative model of income distribution in society is, famine is always "abject poverty". In rural elderly poverty, the "core" is the state of income and expenditure, that is, whether the life of the rural elderly is without income or is less than the average living level in the region. Secondly, because the physiological function of the rural elderly is in a period of declining, the probability of disease is much higher than that of other groups, so its medical expenditure will be far higher than that of other groups. From this point of view, the health level of the elderly in rural areas will also affect their economic status, and "health poverty" has strong linkage with economic poverty. Thirdly, the living standard of the rural elderly depends on their mental state, and the spiritual life is the inner requirement of the life quality of the senior people in the countryside. This is a lack of spiritual comfort in the daily life of the rural elderly, and the cultural entertainment and spiritual comfort from the children, the community and the society can soothe the senior people in the countryside. A sense of loss and emptiness reduces the probability of physical or psychological illness. Therefore, the definition of elderly poverty in rural areas must cover the multidimensional indicators of their economic status, health level and mental 
state. In this paper, the rural elderly poverty is defined as an economic life, a low health level or a poor mental state. The elderly who meet with one of the above three standards can be judged to be a poor man.

\section{Identification of characteristics of the rural elderly poverty.}

The rural elderly is a huge and heterogeneous group. They differ in family status, resource endowment and economic and social environment greatly. Therefore, the reasons for the "poverty" of different rural elderly are in endless variety. The analysis of the characteristics of the rural elderly poverty can enable us to have a detailed understanding of the internal structure and specific representation of the rural elderly poverty.

\subsection{Regional characteristic of the rural elderly poverty.}

Due to geographical location, natural resource endowments, economic policies and other factors, the rural aged poverty shows obvious regional differences. Since the level of rural economic development in the eastern region is higher than that in the central and western regions, the "trickle-down" effect of economic development on the welfare system has made rural social security and the elderly public service in eastern regions more perfect than those in the central and western regions. Due to the harsh environment in the frontier and ethnic areas, the infrastructure is not complete as well as the weak system of the soft power, the development of the region faces the predicament of lack of endogenous motivation and exogenous gravitation. Therefore, its population poverty rate and the incidence of old age poverty are higher.

\subsection{Age characteristics of rural elderly poverty.}

As the age increases constantly, the opportunities for participating in productive labor will become fewer and fewer. As a result, the proportion of the poor elderly living in rural areas increases with age, and the more advanced elderly are more likely to fall into poverty than the less elderly ones. The greater the age, the worse their physical function becomes, which also means the probability of risk of suffering from the disease is increasing, and the more the elderly will spend on medical treatment. Due to the grim trend of "aging" in the process of aging in China, this feature determines that the more advanced elderly will be typical vulnerable and marginalized among all the elderly in the future.

\subsection{Gender characteristics of the rural elderly poverty.}

There is a "female face" in poverty. According to World report on ageing and health of $\mathrm{WHO}(2015)$, women are more likely to fall into poverty than men and less likely to be entitled to a pension in their working lives .In China, the majority of women are engaged in housework, especially after marriage and childbirth. Gender segregation in the social division of labor leads to the disadvantaged position of women in the job market, which undoubtedly extends to their older state, resulting in a higher incidence of poverty among rural women than men. In old age, the sources of income of female elderly are even more unstable.

\section{Analysis of the reasons for the rural elderly poverty.}

Rural old age poverty is a complicated issue. Due to the different economic and social conditions of the elderly in rural areas, the reasons for their falling into poverty will be different. The reasons for the aging population's poverty can be analyzed from the following aspects:

\subsection{Physical function and health decline.}

In rural areas, because of the decline in their physiology, rural residents cannot work in labor, so their sources of income will undoubtedly fall into a precarious and unprotected position. According to the 2010 survey of the urban-rural elderly population in China, over $56 \%$ of rural elderly people cannot farm at 60 because of their physical decline. Nearly $60 \%$ of rural residents stop working at the age of 65 . For a long time, due to the lack of an official social security system, land has been the most 
important source of income for the elderly in the rural areas. Coupled with the relatively low level of education and vocational skills of the elderly in rural areas, they can do no other profession except farming, while stopping farming means that the elderly in rural areas have lost their steady source of income. The decline in physical function also means that the probability of suffering from diseases will increase greatly for the rural elderly. As a result, the medical expenditure will increase substantially compared with that of younger people. According to the statistics from China Science Center for Aging, nearly $70 \%$ of the rural elderly are worried about being no money to cure illness when you are sick.

\subsection{The weakening of family pension function.}

In rural China, the family not only shoulders dual functions of production and life, but also inherits the pension function that should be shouldered by the state, especially during the planned economy of China. With the normalization of family size and population, and the normalization of family population in the context of urbanization and industrialization, the economic support, life care and spiritual comfort gained by the rural elderly from their families have become fewer and fewer. According to the survey, only $11.7 \%$ of rural elderly receive their children's financial support. After being unable to engage in labor production, the economic support of family members to the elderly in rural areas has become the main source of their economic life. However, this situation is becoming increasingly diminished. The miniaturization of the family structure means that the economic supply of old people in the countryside, life care and spiritual comfort become fewer and fewer. Since the rural young people work outside or migrant workers settle in the cities, most rural elderly have become "empty-nest elderly", "left-behind elderly" and their quality of life is greatly reduced because of the lack of the daily care and spiritual consolation from the young people.

\subsection{The lack of social security system.}

There is various definition of poverty, but from an economic point of view, poverty refers to the living predicament due to living beyond one's income and the consequent decline in the quality of life. With certain expenses, increasing the incomes of the elderly through social security system can reduce the incidence of poverty. Conversely, through certain preventive measures and remedial social security systems to reduce their expenditures under certain incomes, it can also play a role in reducing the incidence of poverty. The current rural pension system "new rural cooperative medical system" was introduced in 2009, the pension level of it is only 70 yuan (60 years old and above), and the life replacement rate for rural elderly is less than $13 \%$. According to the survey, over $87 \%$ of rural elders think the new rural cooperative medical system has little or no effect in meeting their daily expenses. In addition, only $16.5 \%$ of the rural elderly enjoy the minimum living allowance or the poverty relief (China Aging Research Center, 2014), and the amount of relief is quite low [15].

\section{Implication for policy.}

In the current context of the "precision poverty alleviation" as the guiding principle of the party and the national poverty alleviation and development work, the analyzing and deconstructing of the rural elderly poverty has become an important part of the tough fight against poverty alleviation. In the context of the social construction of the livelihood oriented society as the motive source of the sustainable development of the economy and society, the theoretical paradigm and research should be applied to embed the policy of solving the poverty with innovation in the rural areas into the social action of precision and poverty alleviation, the transformation of the family structure, the floating and migration of the population, and the background of the interaction and integration of the urban and rural areas should be fully taken into consideration, and a mufti-welfare system should be established based on "family supporting as the foundation, social security as the support and community care as the dependence", to constantly innovate, improve the old age assistance system, and built the safety net of the life of the old people in the countryside.

Firstly, establish a more precise identification mechanism for the elderly. Further deepen the cognition of the forms of poverty in the rural areas and the causes of poverty, set up a more flexible 
and diverse standard for the identification of the elderly poverty, prevent the poverty standards set by the poverty standard, and ensure the precision of the old poverty alleviation policy.

Secondly, advocating the elderly and respecting the family style. We should strengthen the basic role of families in the economic security of the elderly and guide their children to provide stable and appropriate financial support for the elderly. At the same time, we should improve the supply mode of social old-age service in rural areas, vigorously develop home, community and mutual support, promote the combination of medical care, and improve the service quality of the nursing home.

Thirdly, we should enhance the level of social security and social welfare. We should steadily raise standards such as minimum living allowances, social assistance, pensions and preferential treatment in rural areas. In view of the serious illness of the elderly in rural areas and the severe disease returning to the poor, the social medical insurance system has been strengthened to cover the elderly diseases, especially the chronic diseases, and to enhance the economic risk sharing ability of the medical insurance system to the elderly.

Finally, we should continue to promote the construction of the elderly service system in rural communities. By improving the policy system and cultural atmosphere of the aged, filial piety and respecting the elderly in the community, we should strive to build a social atmosphere for the elderly. We should improve the types of community services for the elderly and improve their service quality, to provide more convenient and high-quality services for the elderly.

\section{References}

[1] Yang, J. H., "Population change and poverty in old age', Renmin University of China press 2010 edition.

[2] Organisation for Economic Co-operation and Development. Pensions at a glance 2017: OECD and G20 indicators[R]. Pairs: OECD publishing, 2018.

[3] United Nations. World Population Prospects (2017 edition) [EB/OL]. http://esa.un.org/unpd/ wpp/index.htm.

[4] Qiao, X. C., et al., "Estimation of China’s Elderly Poor Population", Population Studies, No.2, 2005, pp.8-15.

[5] Liu, E. P.,"Movement Trend of the Elderly Poverty and Influencing Factors: Based on Multidimensional Poverty and Comparative Perspective", Journal of Hunan Agricultural University (Social Sciences), No.3, 2018, pp. 77-83.

[6] Yu, X. J., "Active Prevention and Control of Poverty in Old Age", Population and Family Planning, No.5, 2002, pp.16-17.

[7] Wang, N., Zhuang, Y. E.,"Old age Poverty and Support in Rural China", Northwest Population, No.2, 2004, pp.55-58.

[8] Yang, L. X., "A Study on the Population Size of China Old-age Poverty", Population Journal, No.4, 2011, pp.37-45.

[9] Wang, J. Y.,Li, J. B.,"Measurement and Analysis of the Family Poverty in Poverty-Stricken Covered Areas: A Case Study of Yanshan, Taihang Mountain and Hei Long Gang Areas", Chinese Journal of Population Science, No.4,2013,pp.2-13.

[10] Xu, J., Xu, Y. D., "A Study on Elderly Poverty from a Life Course Perspective", Sociological Studies, No.6, 2009, pp.122-144.

[11] Xie, E.,"Public Transfer and Multidimensional Poverty of Older People", China Industrial Economics,No.11,2015,32-46.

[12] Wang, Y., Wang, S. G., "Issues on Aging of Population and Poverty of Aged People in Rural China: Relating research on migration influences" Journal of China Agricultural University (Social Sciences Edition), No.1,2014,pp.108-120. 
[13] May., Li, Z. X., Ma, M.,"Measurement and Factors of Multidimensional Poverty of Older People in China from Community Level and Family Level”, Economic Problems, No.10, 2016, pp27-33.

[14] Liu, Y. W., Wang, R. Q.,"Exacerbate or Ease? Social Security Transfer Payment and Elderly Poverty: The Analysis Based on the Perspective of Urban and Rural Difference", Journal of Shanxi University of Finance and Economics, No.2, 2017,pp.12-21.

[15] Wu,Y.S., Guo, P. "2010 China urban and rural elderly population tracking survey data analysis", China Social Publishing House 2014 edition.

[16] Yu, C. Y.,"What are They Worrying About? Life Risks and Expectations of the Elderly in Chinese Rural Area from Vulnerable Perspective", Journal of Huazhong University of Science and Technology (Social Science Edition), No.1, 2018, 22-31. 